\title{
ANALISIS KREDIBILITAS CELEBRITY ENDORSER DAN DAYA TARIK IKLAN TERHADAP BRAND AWARENESS
}

\author{
Nur Putri Novia Rizky, Kokom Komariah dan Faizal Mulia \\ Universitas Muhammadiyah Sukabumi \\ Email: nurputripute23@gmail.com,ko2mpuspa@yahoo.com dan \\ faizal_88@ummi.ac.id3
}

\begin{abstract}
Abstrak
Seiring dengan beramai-ramainya masyarakat menggunakan smartphone, menjadikan Indonesia menjadi pasar yang sangat potensial bagi berkembangnya pasar smartphone. Hal itu dibuktikan dengan munculnya model smartphone terbaru setiap bulannya. Maka pengusaha telepon genggam pun semakin bersaing untuk menarik konsumen untuk menumbuhkan penjualan. Permasalahan yang ditemui pada Oppo smartphone dari hasil prakuesioner yang dibagikan kepada 12 mahasiswa di Lingkungan Universitas Muhammadiyah Sukabumi yaitu pada brand awareness yang terjadi pada mahasiswa Universitas yang pernah melihat iklan Smartphone Oppo yakni nama merek OPPO tidak dapat dengan cepat muncul didalam pikiran. Permasalahan tersebut diduga dapat terjadi karena daya tarik iklan yang di sampaikan oleh Celebrity endorser kurang menarik dan kurang membentuk brand awareness Smartphone Oppo. Penelitian ini bertujuan untuk menganalisis kredibilitas Celebrity endorser dan daya tarik iklan terhadap brand awareness. Metode penelitian yang digunakan oleh penulis dalam penelitian ini menggunakan purposive sampling yang merupakan bagian dari teknik nonprobability sampling, yakni mahasiswa Universitas Muhammadiyah Sukabumi yang pernah melihat iklan Oppo sejumlah 100 orang. Teknik analisis yang digunakan penulis adalah menggunakan teknik analisis regresi linear berganda, koefisien kolerasi ganda, dan koefisien determinasi dan untuk pengujian hipotesis penulis menggunakan uji statistik secara parsial (uji t). Hasil penelitian menyatakan Celebrity endorser berpengaruh positif secara parsial terhadap Brand awareness pada Smartphone OPPO di Sukabumi. Daya Tarik Iklan berpengaruh positif secara parsial terhadap Brand awareness pada Smartphone OPPO di Sukabumi.
\end{abstract}

Kata kunci: Celebrity endorser; Daya Tarik Iklan; Brand awareness

\section{Pendahuluan}

Perkembangan dunia teknologi informasi yang demikian pesatnya telah membawa manfaat luar biasa bagi kemajuan peradaban umat manusia. Kemajuan teknologi informasi dan komunikasi yang telah dicapai benar-benar telah diakui dan dirasakan memberikan banyak kemudahan dan kenyamanan bagi kehidupan umat manusia khususnya pada bidang pemasaran. Hampir semua aktivitas manusia dapat dilakukan dengan menggunakan smartphone, bahkan untuk berbelanja dan memesan ojek dapat dilakukan dengan mudah menggunakan smartphone (Seftian, 2018). 
Seiring dengan beramai-ramainya masyarakat menggunakan smartphone, menjadikan Indonesia menjadi pasar yang sangat potensial bagi berkembangnya pasar smartphone. Hal itu dibuktikan dengan munculnya model smartphone terbaru setiap bulannya. Maka pengusaha telepon genggam pun semakin bersaing untuk menarik konsumen untuk menumbuhkan penjualan.

Dari website resmi Selular,id, diketahui penguasa pasar ponsel Indonesia selama Q3 2019 berturut-turut adalah Samsung (22\%), Xiaomi (20\%), Oppo (19\%), Vivo (13\%), dan Realme (11\%). Hal tersebut menunjukan bahwa brand Smartphone Oppo masih jauh dibandingkan brand Samsung (Selular.id, 2019).

Perusahaan wajib memiliki cara kreatif dalam beriklan agar dapat menarik perhatian konsumen dan menciptakan ketertarikan terhadap merek. Penggunaan Celebrity endorser dalam iklan diharapkan akan mampu menarik perhatian, sehingga iklan dapat menjadikan suatu brand awareness bagi konsumen (Sintani, 2016). Celebrity endorser dapat mempengaruhi pembentukan sikap positif pada suatu merek (Rosi, 2013). Celebrity endorser juga dapat mempengaruhi konsumen dalam melakukan pembelian suatu produk (Yunianto \& Hidayah, 2014). Pemakaian Celebrity endorser harus melalui beberapa pertimbangan, diantaranya adalah tingkat popularitas selebriti dengan permasalahan apakah selebriti yang dipilih dapat mewakili karakter produk yang sedang diiklankan. Selebriti harus mampu memberikan informasi tentang merek dan atribut produk yang menyenangkan, meyakinkan dan menarik perhatian masyarakat umum. Memanfaatkan selebriti sebagai endorser dirasa memang lebih mudah memengaruhi psikologi konsumsi konsumen. Penggunaan selebriti dalam suatu iklan melibatkan daya tarik dan kredibilitas yang merupakan keunikan tersendiri (Sebayang \& Siahaan, 2008).

Kredibilitas Iklan adalah sebuah sifat yang dimiliki seseorang yang dapat menimbulkan kepercayaan orang lain terhadap dirinya atas kebenaran yang disampaikan melalui iklan. Faktor penting variabel ini adalah keahlihan bintang idola sebagai sumber yang dapat dipercaya dalam penyampaian pesan iklan. Variabel selanjutnya yang mempengaruhi minat beli adalah Daya tarik, dimana daya tarik iklan menjadi prioritas penting dalam menarik hati calon konsumen (Handayani \& Suciningtyas, 2018).

Daya tarik iklan menjadi salah satu hal yang harus diperhatikan. Daya tarik iklan menjadi sarana penunjang dalam program promosi, maka dari itu daya tarik iklan sangat dibutuhkan agar pesan yang disampaikan mempunyai dampak yang diinginkan produsen produk (Dompas, 2019). Celebrity endorser yang digunakan dalam iklan atau gambar dalam iklan merupakan salah satu hal yang mampu membuat orang mau memperhatikan iklan (Mintaraga, 2015). Keunikan atau kreativitas iklan merupakan daya tarik iklan itu sendiri.

Permasalahan yang ditemui pada Oppo smartphone dari hasil prakuesioner yang dibagikan kepada 12 mahasiswa di Lingkungan Universitas Muhammadiyah Sukabumi yaitu pada brand awareness yang terjadi pada mahasiswa Universitas yang pernah melihat iklan Smartphone Oppo yakni nama merek OPPO tidak dapat dengan cepat 
muncul didalam pikiran. Permasalahan tersebut diduga dapat terjadi karena daya tarik iklan yang di sampaikan oleh Celebrity endorser kurang menarik dan kurang membentuk brand awareness Smartphone Oppo.

Berdasarkan penjelasan diatas, penulis berkeinginan untuk meneliti lebih lanjut dari hal tersebut dan tujuan dalam penelitian ini untuk menganalisis kredibilitas Celebrity endorser dan daya tarik iklan terhadap brand awareness.

Penggunaan selebriti dalam sebuah media televisi merupakan alternatif strategi yang tepat untuk memperkenalkan produk kepada konsumen. Menurut (Kotler \& Keller, 2009) Celebrity endorser merupakan penggunaan narasumber (Source) sebagai figure yang menarik atau popular dalam iklan, hal ini merupakan salah satu cara kreatif untuk menyampaikan pesan agar pesan yang disampaikan dapat mencapai perhatian yang lebih tinggi dan dapat diingat.

Dalam penelitian ini, terdapat tiga dimensi Celebrity endorser menurut (Wijaya \& Dharmayanti, 2014) yaitu (1) Kredibilitas (credibility), kredibilitas mengacu pada kecenderungan untuk percaya atau mempercayai endorser; (2) Daya tarik (attractiveness), bukan hanya terletak pada daya tarik fisik semata, tetapi daya tarik meliputi sejumlah karakteristik yang menjadi kelebihan endorser, seperti keterampilan intelektual, sifat-sifat kepribadian, gaya hidup, keatletisan postur tubuh dan sebagainya; (3) Kekuatan (power), merupakan kharisma yang dipancarkan oleh Celebrity endorser yang mampu mempengaruhi sikap, pemikiran dan perilaku konsumen karena pesan atau pernyataan endorser saat membawakan citra produk.

Penelitian yang dilakukan oleh (Nugroho, 2013), menyatakan bahwa terdapat pengaruh positif dan signifikan Celebrity endorser terhadap brand awareness (Nugroho, 2013)

H1: Terdapat pengaruh Celebrity endorser terhadap brand awareness pada produk Smartphone Oppo Sukabumi.

Iklan sudah menjadi hal biasa yang kita lihat di media cetak, media elektronik maupun media online. Morissan dalam (Hartono, 2016) daya tarik iklan merupakan sesuatu yang menggerakkan orang, berbicara mengenai keinginan atau kebutuhan mereka dan membangkitkan ketertarikan.

Menurut Bendixen dalam (Hartono, 2016) untuk melakukan pendekatan kepada konsumen dan agar pesan mudah diterima, perlu juga digunakan daya tarik (appeals). Daya tarik yang digunakan dalam pesan iklan harus memiliki tiga karakteristik yakni (1) daya tarik itu bermakna (meaningful), yaitu menunjukkan manfaat yang membuat konsumen lebih menyukai atau lebih tertarik pada produk itu; (2) daya tarik itu harus khas/berbeda (distinctive), harus menyatakan apa yang membuat produk lebih baik dari produk-produk pesaing; (3) pesan iklan itu harus dapat dipercaya (believable), yaitu menunjukkankebenaran iklan mengenai produk yang ditampilkan.

Penelitian yang dilakukan oleh (Nugroho, 2013), menyatakan bahwa terdapat pengaruh positif dan signifikan daya tarik iklan terhadap brand awareness (Nugroho, 2013). 
H2 : Terdapat pengaruh daya tarik iklan terhadap brand awareness pada produk Smartphone Oppo Sukabumi.

Kesadaran merek (brand awareness) adalah kesanggupan seorang pembeli untuk mengenali atau mengingat kembali bahwa suatu merek merupakan bagian dari kategori produk tertentu. Konsumen cenderung membeli merek yang sudah dikenal karena merasa aman dengan sesuatu yang sudah dikenal (Basid, Hasiolan, \& Haryono, 2015).

Brand awareness menurut Keller dalam (Willianto.k \& Semuel.H, 2005) terdiri dari beberapa pengertian, yaitu: (1) konsumen paham seperti apa merek itu; (2) dapat mengenali merek diantara merek pesaing; (3) sadar akan keberadaan merek; (4) konsumen bisa membayangkan ciri merek dengan cepat .

Model penelitian kuantitatif atau bentuk paradigma sederhana dimana terdapat tiga variabel yaitu variabel Celebrity endorser dan daya tarik iklan sebagai variabel independent/variabel bebas yang ditunjukkan dengan (X) dan variabel brand awareness sebagai variabel dependent/ variabel terikat yang ditunjukkan dengan (Y) dapat digambarkan sebagai berikut :

\section{Gambar 1 \\ Model Penelitian}

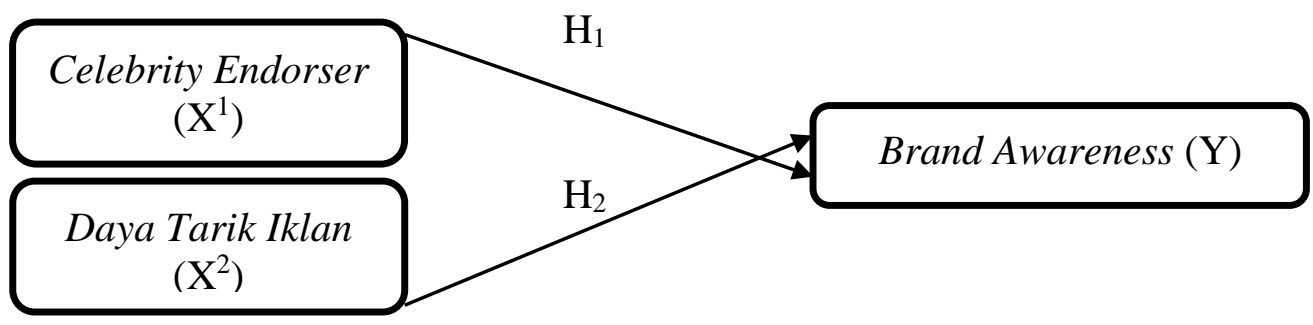

Gambar 1

Model Penelitian

\section{Metode Penelitian}

Penelitian ini dilakukan pada mahasiswa Universitas Muhammadiyah Sukabumi yang pernah melihat iklan Oppo sejumlah 100 orang. Metode penelitian yang digunakan oleh penulis dalam penelitian ini menggunakan purposive sampling yang merupakan bagian dari teknik nonprobability sampling. Teknik analisis yang digunakan penulis adalah menggunakan teknik analisis regresi linear berganda, koefisien kolerasi ganda, dan koefisien determinasi dan untuk pengujian hipotesis penulis menggunakan uji statistik secara parsial (uji t).

\section{Hasil dan Pembahasan}

\section{A. Hasil Analisis Regresi Linear Berganda}

Regresi linear berganda berguna untuk meneliti seberapa besar pengaruh beberapa variabel yang berkorelasi dengan variabel yang diuji. Berikut ini merupakan hasil dari regresi linear berganda yang ditunjukan pada tabel 1: 


\section{Tabel 1}

Hasil Uji Regresi Linear Berganda

\begin{tabular}{|c|c|c|c|c|c|}
\hline \multirow[b]{3}{*}{ Model } & \multicolumn{3}{|c|}{ Coefficients $^{\mathrm{a}}$} & \multirow[b]{3}{*}{$\mathrm{t}$} & \multirow[b]{3}{*}{ Sig. } \\
\hline & \multicolumn{2}{|c|}{$\begin{array}{l}\text { Unstandardized } \\
\text { Coefficients }\end{array}$} & \multirow{2}{*}{$\begin{array}{c}\text { Standardized } \\
\text { Coefficients } \\
\text { Beta }\end{array}$} & & \\
\hline & $\mathrm{B}$ & Std. Error & & & \\
\hline 1 (Constant) & 3.234 & 1.178 & & 2.745 & .007 \\
\hline $\begin{array}{l}\text { Celebrity } \\
\text { endorser }\end{array}$ & .275 & .066 & 484 & 4.144 & .000 \\
\hline Daya Tarik Iklan & .368 & .147 & 293 & 2.507 & .014 \\
\hline
\end{tabular}

a. Dependent Variable: Brand awareness

Dari hasil uji regresi linear berganda diatas dapat diperoleh persamaan sebagai berikut:

$$
\mathrm{Y}=3,234+0,275 \mathrm{X}_{1}+0,368 \mathrm{X}_{2}
$$

\section{Koefisien Determinasi $\left(\mathbf{R}^{2}\right)$}

Tabel 2

Hasil Koefesien Determinasi

\begin{tabular}{ll|r|r|r}
\hline \multicolumn{5}{c}{ Model Summary } \\
\hline Model & $\mathrm{R}$ & $\mathrm{R}$ Square & $\begin{array}{c}\text { Adjusted } R \\
\text { Square }\end{array}$ & $\begin{array}{l}\text { Std. Error of } \\
\text { the Estimate }\end{array}$ \\
\hline 1 & $.742^{\mathrm{a}}$ & .551 & .542 & 2.04195 \\
\hline
\end{tabular}

a. Predictors: (Constant), Daya Tarik Iklan, Celebrity endorser

Hasil tabel 2 menunjukan besarnya nilai Adjusted $\mathrm{R}^{2}$ adalah 0,542; Hal tersebut menunjukan 54,2\% variabel Brand awareness dapat dijelaskan oleh kedua variabel independen yaitu Celebrity endorser dan Daya Tarik Iklan. Sementara $45,8 \%$ berasal dari faktor yang tidak diteliti dalam penelitian.

\section{Koefisien Kolerasi Ganda}

\section{Tabel 3}

Hasil Koefesien Kolerasi Ganda

\section{Model Summary}

\begin{tabular}{lc|c|c|c}
\hline Model & $\mathrm{R}$ & $\mathrm{R}$ Square & $\begin{array}{c}\text { Adjusted } R \\
\text { Square }\end{array}$ & $\begin{array}{l}\text { Std. Error of } \\
\text { the Estimate }\end{array}$ \\
\hline 1 & $.742^{\mathrm{a}}$ & .551 & .542 & 2.04195 \\
\hline $\begin{array}{l}\text { a. Predictors: (Constant), Daya Tarik Iklan, Celebrity } \\
\text { endorser }\end{array}$
\end{tabular}

Hasil tabel 3 diatas diperoleh angka R Sebesar 0,742 berada pada kategori 0,60-0,799. Hal ini menunjukan bahwa adanya hubungan yang kuat yang terjadi antara Celebrity endorser dan Daya Tarik Iklan dengan Brand awareness. 


\section{Uji Signifikasi Secara Parsial (Uji t)}

\section{Tabel 4}

Hasil Uji Signifikasi Secara Parsial (Uji t)

\begin{tabular}{|c|c|c|c|c|c|}
\hline \multicolumn{6}{|c|}{ Coefficients $^{\mathrm{a}}$} \\
\hline \multirow[b]{2}{*}{ Model } & \multicolumn{2}{|c|}{$\begin{array}{l}\text { Unstandardized } \\
\text { Coefficients }\end{array}$} & \multirow{2}{*}{$\begin{array}{c}\text { Standardized } \\
\text { Coefficients } \\
\text { Beta } \\
\end{array}$} & \multirow[b]{2}{*}{$\mathrm{T}$} & \multirow[b]{2}{*}{ Sig. } \\
\hline & $\mathrm{B}$ & Std. Error & & & \\
\hline $\begin{array}{ll}1 & \text { (Constant) } \\
\end{array}$ & 3.234 & 1.178 & & 2.745 & .007 \\
\hline $\begin{array}{l}\text { Celebrity } \\
\text { endorser }\end{array}$ & .275 & .066 & .484 & 4.144 & .000 \\
\hline Daya Tarik Iklan & .368 & .147 & .293 & 2.507 & .014 \\
\hline
\end{tabular}

a. Dependent Variable: Brand awareness

Berdasarkan tabel 4 diatas, hasil uji t yang dilakukan pada variabel Celebrity endorser menghasilkan nilai dengan sig. $0,000<0,05$; nilai thitung $_{4,144<}$ $\mathrm{t}^{\text {tabel }} 1,98447$ nilai tersebut menunjukan bahwa Celebrity endorser berpengaruh positif dan signifikan secara parsial terhadap Brand awareness. Variabel Daya Tarik Iklan memiliki nilai sig. $0,014<0,05$; nilai $\mathrm{t}^{\text {hitung }} 2,507<\mathrm{t}^{\text {tabel }} 1,98447$, artinya Daya Tarik Iklan berpengaruh positif dan signifikan terhadap Brand awareness.

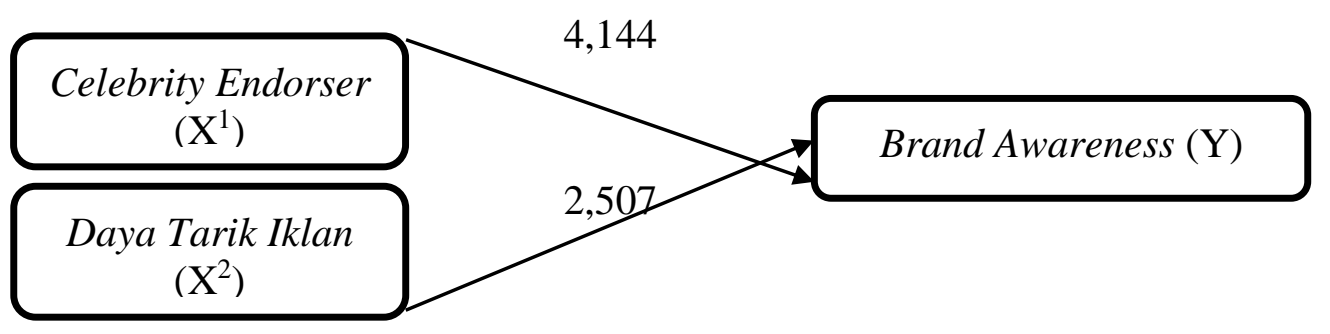

\section{Gambar 4 \\ Brand awareness}

\section{Kesimpulan}

Dari penelitian yang dilakukan, hasil penelitian ini menunjukan Celebrity endorser berpengaruh positif secara parsial terhadap Brand awareness pada Smartphone OPPO di Sukabumi. Daya Tarik Iklan berpengaruh positif secara parsial terhadap Brand awareness pada Smartphone OPPO di Sukabumi. Nilai Adjusted $\mathrm{R}^{2}$ adalah 0,542; Hal tersebut menunjukan 54,2\% variabel Brand awareness dapat dijelaskan oleh kedua variabel independen yaitu Celebrity endorser dan Daya Tarik Iklan. Sementara $45,8 \%$ berasal dari faktor yang tidak diteliti dalam penelitian. 


\section{BIBLIOGRAFI}

Basid, Chamid Abdul, Hasiolan, Leonardo Budi, \& Haryono, Andi Tri. (2015). Pengaruh Citra Merek, Sikap Merek Dan Kesadaran Merek Terhadap Ekuitas Merek Susu Frisian Flag (Studi Kasus di Kecamatan Tembalang Semarang).

Dompas, Fheliska Sarrah. (2019). Pengaruh Daya Tarik Iklan Shopee Versi "Shopee For Men” Terhadap Brandawareness (Survei pada Kaum Pria Pengunjung Kota Kasablanka). Universitas Pembangunan Nasional Veteran Jakarta.

Handayani, Tri, \& Suciningtyas, Santi. (2018). Analisis Faktor-Faktor Yang Mempengaruhi Minat Beli Pada Dealer Comal Abadi Motor Taman-Pemalang. Syntax Literate; Jurnal Ilmiah Indonesia, 3(9), 123-137.

Hartono, Kefas. (2016). Pengaruh Daya Tarik Iklan Dan Selebriti Endorser Terhadap Kesadaran Merek Dan Dampaknya Terhadap Brand Attitude Minuman Dalam Kemasan. 53(9), 1689-1699. https://doi.org/10.1017/CBO9781107415324.004

Kotler, Philip, \& Keller, Kevin Lane. (2009). Manajemen pemasaran Jilid 1. In Jakarta.

Mintaraga, Susan. (2015). Hubungan Antara Penggunaan Celebrity endorser Pada Iklan Beauty Product Dengan Pembentukan Body Image Konsumen Remaja Perempuan. Competence: Journal of Management Studies, 9(1).

Nugroho, Septiyo Aji. (2013). Analisis Pengaruh Daya Tarik Iklan Dan Kekuatan Celebrity endorser Terhadap Brand awareness Dan Dampaknya Terhadap Brand Attitude Handphone Nokia (Studi Kasus pada Mahasiswa dan Mahasiswi Fakultas Ekonomika dan Bisnis Universitas Diponegoro Semarang ). Diponegoro Journal Of Management, 2, 1-11.

Nugroho, Septiyo Aji, \& Mudiantono, Mudiantono. (2013). (Studi Kasus Pada Mahasiswa dan Mahasiswi analisis pengaruh daya tarik iklan dan kekuatan Celebrity endorser terhadap brand awareness dan dampaknya terhadap brand attitude handphone nokia Fakultas Ekonomika Dan Bisnis Universitas Diponegoro Semarang). Fakultas Ekonomika dan Bisnis.

Rosi, Fatchur. (2013). Analisis Perbandingan Pengaruh Endorser terhadap Sikap pada Merek Shampo Sunsilk dan Shampo Pantene. Jurnal Ilmu Manajemen (JIM), 1(1).

Sebayang, Siahaan Simon, \& Siahaan, Simon Darman O. (2008). Pengaruh Celebrity endorser terhadap keputusan pembelian sepeda motor merek Yamaha Mio pada Mio Automatik Club (MAC) Medan. Jurnal Manajemen Bisnis, 1(3), 117-125.

Seftian, Jefry. (2018). Pengaruh Celebrity Endorsement (Raisa Andriana) Terhadap Purchase Intention Dengan Brand Image Sebagai Variabel Intervening Pada Produk Oppo Smartphone.

Selular.id. (2019). Top 5 Vendor Smartphone di Indonesia Q3-2019. Retrieved from 
https://selular.id/2019/11/top-5-vendor-smartphone-di-indonesia-q3-2019/

Sintani, Laurencia. (2016). Pengaruh Penggunaan Celebrity endorser Isyana Sarasvati Dalam Iklan "Isyana vs Gangster" Terhadap Brand awareness Masyarakat Surabaya. Jurnal E-Komunikasi, 4(1).

Wijaya, Noviany, \& Dharmayanti, Diah. (2014). Analisa Efektivitas Iklan Kosmetik Wardah Dengan Menggunakan Consumer Decision Model (Cdm). Jurnal Manajemen Pemasaran Petra, 2(1).

Willianto.k \& Semuel.H. (2005). Analisa Pengaruh Brand Performance Terhadap Repurchase Intention Dengan Competitive Advantage Sebagai Variabel Mediasi Pada Erha Dermatology Surabaya. Analisa Pengaruh Brand Permormance Terhadap Repurchase Intention Dengan Competitive Advantage Sebagai Variabel Mediasi Pada Erha Dematology Surabaya.

Yunianto, Tri, \& Hidayah, Arini. (2014). Analisis Perbandingan Penggunaan Celebrity endorser Dan Typical-Person Endorser Iklan Televisi Dan Pengaruhnya Terhadap Brand Image Produk Shampo Clear. Media Ekonomi, 14(1). 